\title{
Cardiac stroke volume during exercise measured by Doppler echocardiography: comparison with the thermodilution technique and evaluation of reproducibility
}

\author{
HALFDAN IHLEN, KNUT ENDRESEN, SVEIN GOLF, \\ SI GURD N I T T ER - H A UGE \\ From the Medical Department B, Rikshospitalet, University Hospital, Oslo, Norway
}

SUMMARY Cardiac stroke volume was measured simultaneously by Doppler echocardiography and thermodilution in patients with severe coronary artery disease. One group (20 patients) was examined during supine exercise at $25 \mathrm{~W}$ and a second group (20 patients) during sitting exercise at $25 \mathrm{~W}$ and $50 \mathrm{~W}$. In a third group (10 patients) the reproducibility of the non-invasive stroke volume estimate was determined during upright exercise. There was a considerable variation between results obtained with the invasive and non-invasive technique at rest and during exercise, but no systematic differences were found. Analysis of variance showed that no systematic differences between ultrasonic results were introduced by two observers or by measurements on different days. The coefficient of variation between any pairs of Doppler measurements in each patient was $6 \%$.

These findings demonstrate that the ultrasonic technique is suitable for detecting changes in stroke volume induced by low load exercise in patients with severe angina pectoris.

Previous studies have shown that Doppler echocardiography can be used to measure the cardiac response to exercise ${ }^{1-4}$; however, the results were not compared with those of invasive methods. In addition, few data are available on the reproducibility of blood flow measurements during exercise. ${ }^{14}$ We have compared stroke volume results obtained by Doppler echocardiography with those obtained simultaneously by the thermodilution technique in patients during exercise while supine and sitting. We have also measured the reproducibility of Doppler echocardiography for measuring stroke volume during exercise in the sitting position.

\section{Patients and methods}

P A T I E N T S

Seventy six men (mean age 49 , range 29-63) under-

Requests for reprints to Dr Halfdan Ihlen, Medical Department B, Rikshospitalet, 0027 Oslo 1, Norway.

Accepted for publication 7 July 1987 going cardiac catheterisation for the evaluation of severe angina pectoris gave their informed consent to the study. All patients were in sinus rhythm and none had valvar heart disease or intracardiac shunts. Coronary angiography revealed one vessel, two vessel, and three vessel disease in five, 12 , and 59 patients respectively. Sixty nine patients were taking one or several cardioactive drugs-nitrates, $\beta$-adrenergic blockers, or calcium channel blockers. In four patients the results of Doppler recordings in the supine resting position were technically inadequate and in 22 patients recordings obtained in the sitting resting position were unsatisfactory. No patients were excluded during the exercise tests. Thus 50 patients were included in the study.

\section{S T U D Y D E S I G N}

Doppler and thermodilution measurements of cardiac output measurements were done simultaneously both at rest and during exercise on a bicycle ergometer.

Supine position (20 patients): All patients were exercised at $25 \mathrm{~W}$ for $4 \mathrm{~min}$.

Sitting position (20 patients): All patients were 
exercised at $25 \mathrm{~W}$ for $4 \mathrm{~min}$ before the measurements, and in 18 of them the procedure was repeated at $50 \mathrm{~W}$.

Reproducibility (10 patients): Doppler measurements were performed during exercise in the sitting position. After $4 \mathrm{~min}$ work at $50 \mathrm{~W}$, the Doppler measurements were obtained by one observer and repeated immediately by another who was unaware of the first results. An identical procedure was performed after an interval of 1-21 days (mean nine days) at the same time of the day. The drug treatment was not changed.

\section{O P P LER E C H O CARDIOGRAPH Y}

A single Doppler instrument (Vingmed SD 100) was used from the suprasternal approach to measure blood velocities just distal to the aortic valve by a pulsed technique. ${ }^{56}$ The analogue curve of the maximal velocity. was overlaid on the spectral display. ${ }^{7}$ This velocity was integrated automatically and the integrator was reset by the electrocardiogram before each beat. The integral was read at the closure of the aortic valve, which was easily seen in the velocity spectrum, and the average of 10 consecutive beats was calculated.

A phased array cross sectional instrument (Irex III) was used to measure the diameter of the aortic orifice in the parasternal long axis view. ${ }^{568}$ Measurements were obtained during three consecutive beats at the point in the cardiac cycle when the orifice echoes were most distinctly seen; the average was used to calculate the orifice area. The diameter was determined only at rest, and this value was used during all stroke volume calculations.

\section{T H E R O DILUT I ON T E C H N Q UE}

A thermodilution catheter (Baltherm or Torktherm, Elecath) was positioned in the pulmonary artery from a basilic vein (sitting position) or femoral vein (supine position). Cardiac stroke volume was calculated from three consecutive measurements of cardiac output using a Elecath Cardiac Output Computer $4000 .^{5}$

\section{A L C U L A T I O N S}

All recordings were obtained blindly and were not read until the study of each group was completed. Aortic orifice area (A) was calculated as: $A=\pi \times$ $(\mathrm{D} / 2)^{2}$, where $\mathrm{D}$ is the aortic orifice diameter. Ultrasonic cardiac stroke volume $\left(\mathrm{SV}_{\mathrm{d}}\right)$ was calculated as: $S V_{d}=A \times S V I$, where SVI is systolic velocity. integral.

\section{S T A T I S T I C S}

Invasive and non-invasive results were compared by the method of Bland and Altman. ${ }^{9}$ The variability of
Doppler estimates of stroke volume was calculated by analysis of variance (BMDP3V) and presented as coefficients of variation.

Wilcoxon's signed rank test was used for paired group comparison, and a $p$ value $<0.05$ was considered to be statistically significant.

\section{Results}

\section{S U P I N E P O S I T I O N}

At rest the differences between each pair of stroke volume estimates measured by the two techniques were distributed equally around zero; the mean difference being $1.7 \mathrm{ml}$ (fig 1 ). The $95 \%$ confidence limits for the differences (mean (2) SD) gave limits . of agreement of -26 to $29 \mathrm{ml} \mathrm{(}-33 \%$ to $36 \%$ of the mean stroke: volume). During exercise the mean difference between each pair of stroke volume estimates was - $0.3 \mathrm{ml}(\mathrm{NS})$ and the limits of agreement were $-26 \mathrm{ml}$ to $26 \mathrm{ml}(-32 \%$ to $32 \%)$.

Stroke volume did not change during exercise with any of the measurement techniques (fig 2); cardiac output increased because of a $45 \%$ increase in heart rate.

\section{S I T T I N G POS I T ION}

At rest the differences between each pair of stroke volume estimates were uniformly distributed around zero; the mean difference being $-1 \mathrm{ml}$ (fig 3). During exercise the mean difference was $-8 \mathrm{ml}$ at $25 \mathrm{~W}$ and $-4 \mathrm{ml}$ at $50 \mathrm{~W}$. The first

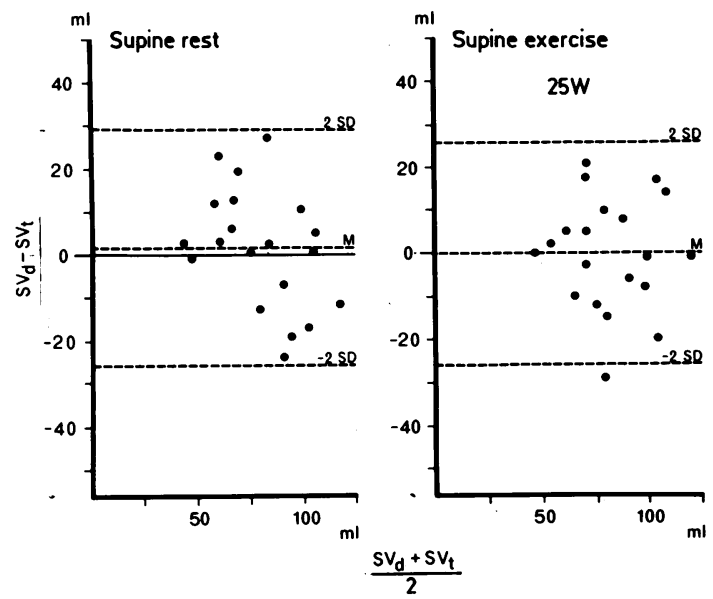

Fig.1 Difference between stroke volume measured by Doppler echocardiography and thermodilution ( $\left.S V_{d}-S V_{\mathrm{t}}\right)$ versus the mean of the two measurements $\left(\left(S V_{\mathrm{d}}+S V_{\mathrm{t}}\right) \div 2\right)$ during supine rest and during supine exercise at $25 \mathrm{~W}$. Broken lines indicate the mean and the $95 \%$ range of the differences between the two measurements. 


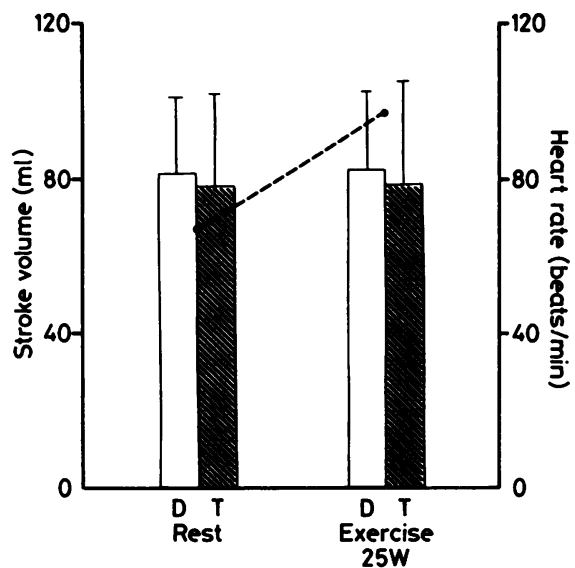

Fig 2 Mean (1 SD) stroke volume measured by Doppler echocardiography (D) and thermodilution ( $T$ ) at supine rest and during supine exercise at $25 \mathrm{~W}$ in 20 patients. Closed circles indicate mean heart rate.

difference was barely significant $(p=0.04)$ with the thermodilution technique giving slightly higher results. The difference at $50 \mathrm{~W}$ exercise was not significant. The limits of agreement were $-21 \mathrm{ml}$ to $18 \mathrm{ml}(-37 \%$ to $32 \%)$ at sitting rest, increasing to $-43 \mathrm{ml}$ to $27 \mathrm{ml} \mathrm{(}-56 \%$ to $35 \%$ ) during $25 \mathrm{~W}$ exercise, and $-40 \mathrm{ml}$ to $31 \mathrm{ml}(-49 \%$ to $38 \%$ ) during $50 \mathrm{~W}$ exercise.

Both techniques showed a considerable increase

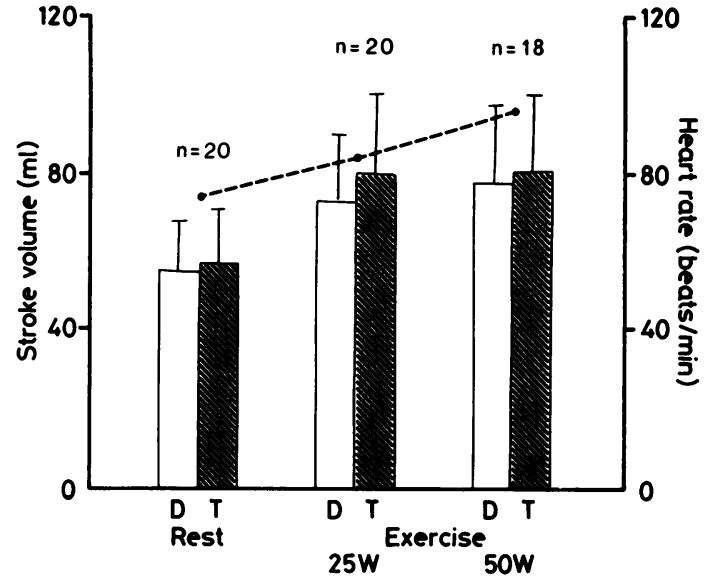

Fig 4 Mean (1 SD) stroke volume measured by Doppler echocardiography (D) and thermodilution ( $T$ ) at upright rest and during upright exercise at $25 \mathrm{~W}$ and $50 \mathrm{~W}$. Closed circles indicate mean heart rate.

in stroke volume during $25 \mathrm{~W}$ exercise (fig 4) and cardiac output rose because of an increase in both stroke volume and heart rate. No further change in stroke volume was measured when the patients were exercised at $50 \mathrm{~W}$ and the increased cardiac output was the result of a higher heart rate.

R E P R O D U C I B I L I T Y

Mean (1SD) stroke volume was $105(18) \mathrm{ml}$ during
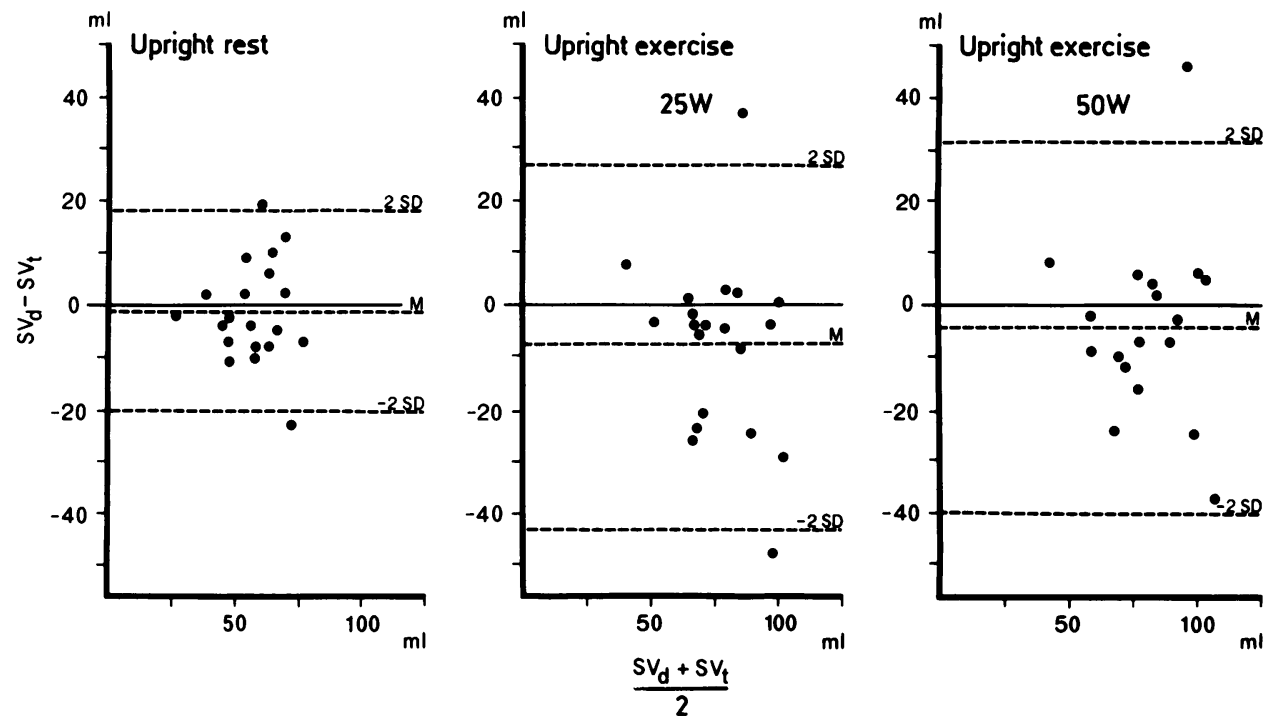

Fig 3 Difference between stroke volume measured by Doppler echocardiography and thermodilution $\left(S V_{\mathrm{d}}-S V_{\mathrm{t}}\right)$ versus the mean of the two measurements $\left(\left(S V_{\mathrm{d}}+S V_{\mathrm{t}}\right) \div 2\right)$ at upright rest and during upright exercise at $25 \mathrm{~W}$ and $50 \mathrm{~W}$. Broken lines indicate the mean and the $95 \%$ range of the differences between the two measurements. 
Table Doppler estimates of stroke volume ( $\mathrm{ml}$ ) obtained during sitting exercise $(50 \mathrm{~W})$ by two independent observers and on two different days (an average of nine days apart)

\begin{tabular}{|c|c|c|c|c|}
\hline \multirow[b]{2}{*}{ Patient No } & \multicolumn{2}{|l|}{ Day 1} & \multicolumn{2}{|l|}{ Day 2} \\
\hline & $\begin{array}{l}\text { Observer } \\
A\end{array}$ & $\begin{array}{l}\text { Observer } \\
B\end{array}$ & $\begin{array}{l}\text { Observer } \\
A\end{array}$ & $\begin{array}{l}\text { Observer } \\
B\end{array}$ \\
\hline $\begin{array}{l}1 \\
2 \\
3 \\
4 \\
5 \\
6 \\
7 \\
8 \\
9 \\
10 \\
\text { Mean (1SD) }\end{array}$ & $\begin{array}{r}106 \\
124 \\
99 \\
116 \\
75 \\
80 \\
110 \\
119 \\
128 \\
91 \\
105(18)\end{array}$ & $\begin{array}{l}105 \\
113 \\
104 \\
108 \\
84 \\
79 \\
115 \\
119 \\
124 \\
97 \\
105(15)\end{array}$ & $\begin{array}{l}110 \\
133 \\
100 \\
103 \\
95 \\
79 \\
115 \\
106 \\
131 \\
88 \\
106(17)\end{array}$ & $\begin{array}{c}107 \\
122 \\
100 \\
95 \\
82 \\
80 \\
108 \\
99 \\
144 \\
86 \\
102(20)\end{array}$ \\
\hline
\end{tabular}

exercise in the upright position (table). There was no significant difference between measurements obtained by the two observers or between measurements performed on different days. The variance of the differences between any pairs of measurements in each patient was $42 \mathrm{ml}$ and the coefficient of variation was $6 \cdot 2 \%$. The coefficient of variation was $0.9 \%$ between the two observers and $0.3 \%$ between the two days.

The coefficient of variation in individual patients was calculated from the 10 beats which were included in each estimate of the stroke volume. The mean of these coefficients of variation in all the patients was $4 \cdot 3(1 \cdot 2) \%$.

\section{Discussion}

Whatever technique is used to measure cardiac output at rest there are technical difficulties ${ }^{1011}$; and measurement during exercise causes additional problems that particularly affect the ultrasonic method. The thoracic movements produced by exercise and increased respiration may lead to blood velocity being measured at different positions in the aorta. These thoracic movements are probably more important during upright than supine exercise because the chest is partially fixed in the lying position. In the present study, the effect of this was probably unimportant because there was little variation in beat to beat stroke volume during sitting exercise. The velocity profile may be skewed during exercise. ${ }^{12}$ Theoretically, however, when flow increases the velocity profile is probably unchanged at the level of the aortic orifice. ${ }^{13}$

During exercise the intraluminar aortic pressure increases and there may be considerable cyclic changes in cross sectional aortic area at the site of velocity measurement. It is extremely difficult to measure this area during exercise. This difficulty can be partly counteracted by our method which measures flow at the level of the aortic orific. This part of the fibrous skeleton of the heart is probably little affected by pressure changes, and we have previously shown that the diameter of the orifice is unchanged during the cardiac cycle and by infusion of positive inotropic drug. ${ }^{6}$ Accordingly, we determined the diameter only once in each patient, assuming that it was unchanged during the course of the study.

In the present study there were no systematic differences between the estimates of stroke volume obtained by Doppler echocardiography and by the thermodilution technique either at rest or during steady state exercise of low to moderate intensity. The only exception was a barely significant difference at the smallest work level during exercise in the sitting position. To test the agreement between these two techniques of measurement, most earlier reports used correlation coefficient and linear regression analysis. ${ }^{514-16}$ The data in the present study were compared by a more appropriate statistical method. ${ }^{9}$

We found considerable variation between results obtained by the two techniques, and this variation was of the same magnitude at rest and during exercise in the supine position. Application of the Bland and Altman analysis to earlier reports by us and others showed similar variations. ${ }^{514-16}$ The present study also showed an even larger variation during exercise in the sitting position. This finding might be due to higher stroke volume estimates. However, when the difference was calculated as a percentage of the mean stroke volume, larger variation during exercise in the sitting position remained.

The reproducibility of the ultrasonic stroke volume was examined during sitting exercise using the same model for repeated stroke volume measurements as previously reported. ${ }^{7}$ The coefficient of variation was $9 \%$ at rest ${ }^{7}$ whereas it was $6 \%$ in the present study, showing that the variability of the ultrasonic method is not increased by upright exercise. No bias was introduced when velocities were measured by two observers and on different days, which also accords with our previous work. ${ }^{7}$ This good reproducibility of ultrasonic estimates of stroke volume during rest and sitting exercise demonstrates the feasibility of Doppler echocardiography in determining stroke volume despite the considerable variation between the results obtained with the two methods.

Measurement of cardiac output is of particular interest in patients with advanced heart disease and may be used to evaluate drug effects. In the present study, the exercise load was kept low to avoid myo- 
cardial ischaemia and interference with steady state haemodynamics. Our results suggest that measurements of cardiac output by the ultrasonic technique may be useful during ischaemia induced by low load exercise. A comparative study of the ultrasonic and thermodilution technique during higher exercise levels than used in this study is necessary, however.: Previous reports have shown the technical difficulties of Doppler recordings at high load exercise. $^{2} 3$

In most patients cardiac output could be estimated during supine low load exercise. However, the changes in stroke volume were small both in normal individuals and in cardiac patients as previously shown. ${ }^{117}$ On the other hand, there is usually a considerable increase in the stroke volume response during upright exercise and such a measurement might be more sensitive to decreased cardiac function. ${ }^{1}$ The approach is limited by the fact that the Doppler technique is unsuitable in about one third of the patients during upright exercise. Therefore, further research is needed to determine whether the supine or the upright position is more suitable for testing cardiac function during exercise when this is measured by the ultrasonic technique.

We thank Professor Lars Walløe for statistical advice. 


\section{References}

1 Loeppky JA, Greene ER, Hoekenga E, Caprihan A, Luft UC. Beat-by-beat stroke volume assessment by pulsed Doppler in upright and supine exercise. $J$ Appl Physiol 1981;50:1173-82.

2 Daley PJ, Sagar KB, Wann LS. Doppler echocardiographic measurement of flow velocity in the ascending aorta during supine and upright exercise. Br Heart $J$ 1985;54:562-7.

3 Gardin JM, Kozlowski J, Dabestani A, et al. Studies of Doppler aortic flow velocity during supine bicycle exercise. Am J Cardiol 1986;57:327-32.

4 Bryg RJ, Labovitz AJ, Mehdirad AK, Williams GA, Chaitman BR. Effect of coronary artery disease on Doppler-derived parameters of aortic flow during upright exercise. Am J Cardiol 1986;58:14-9.

5 Ihlen H, Amlie JP, Dale J, et al. Determination of cardiac output by Doppler echocardiography. Br Heart $J$ 1984;51:54-60.

6 Ihlen H, Myhre E, Amlie JP, Forfang K, Larsen S. Changes in left ventricular stroke volume measured by Doppler echocardiography. $\mathrm{Br}$ Heart $J$ 1985;54:378-83.

7 Ihlen $H$, Endresen K, Myreng Y, Myhre E. Reproducibility of cardiac stroke volume estimates by Doppler echocardiography. $A m$ J Cardiol 1987;59:975-8.

8 Rein AJJT, Hsieh KS, Elixson M, et al. Cardiac output estimates in the pediatric intensive care unit using a continuous-wave Doppler computer: validation and limitations of the technique. Am Heart $J$ 1986;112: 97-103.

9 Bland JM, Altman DG. Statistical methods for assessing agreement between two methods of clinical measurement. Lancet 1986;i:307-10.
10 Schuster AH, Nanda NC. Doppler echocardiographic measurement of cardiac output: comparison with a non-golden standard. Am J Cardiol 1984;53:257-9.

11 Mackenzie JD, Haites NE, Rawles JM. Method of assessing the reproducibility of blood flow measurement: factors influencing the performance of thermodilution cardiac output computers. Br Heart $\mathrm{J}$ 1986;55:14-24.

12 Falsetti HL, Carroll RJ, Swope RD, Chen CJ. Turbulent blood flow in the ascending aorta of dogs. Cardiovasc Res 1983;17:427-36.

13 Wille SØ, Walløe L. Pulsatile pressure and flow in arterial stenosis simulated in a mathematical model. $J$ Biomed Eng 1981;3:17-24.

14 Goldberg SJ, Sahn DJ, Allen HD, Valdes-Cruz LM, Hoenecke H, Carnahan Y. Evaluation of pulmonary and systemic blood flow by 2-dimensional Doppler echocardiography using fast Fourier transform spectral analysis. Am J Cardiol 1982;50:1394-400.

15 Huntsman LL, Stewart DK, Barnes SR, Franklin SB, Colocousis JS, Hessel EA. Noninvasive Doppler determination of cardiac output in man. Clinical validation. Circulation 1983;67:593-602.

16 Chandraratna PA, Nanna M, McKay C, et al. Determination of cardiac output by transcutaneous continuous-wave ultrasonic Doppler computer. Am J Cardiol 1984;53:234-7.

17 Wang Y, Marshall RJ, Shepherd JT. The effect of changes in posture and of graded exercise on stroke volume in man. J Clin Invest 1960;39:1051-61. 